\title{
STUDY OF SPATIAL DISTRIBUTION OF VEGETATION INDEX OF AL- ZAWRA AMMUSEMENT PARK IN BAGHDAD AREA USING GEOTECHNIQUES
}

\author{
M. A. Al-fatlawi \\ Researcher \\ S. N. Jasim \\ Asst. Prof. \\ Dept. of Horticulture and landscape Gardening Coll. of Agric., Univ. of Baghdad, Iraq. \\ ahmedalfatlawi93@gmail.com
}

\section{ABSTRACT:}

The recent needs using new technologies depending on the geomatics and geotachnologies represented by remote sensing (RS) and geographic information system (GIS) as a tool to manage urban parks green spaces as it allows to collect a lot of data easily and quickly. Also, geoanalyzing and interpreting them to improve these spaces role in urban cities. Normalized differences of vegetation index (NDVI) is considered as one of the most important geotechnical applications and a mean to monitor and interpret changes occurring in this land cover. NDVI has been studied by using Arc GIS v10.3 and the image taken by landsat 8 of OLI sensor at spatial resolution $30 * 30 \mathrm{~m}^{2}$. NDVI result showed that it was ranging between $(0-\mathbf{- 0 . 6 )}$ in no vegetative cover areas such as water surfaces and bare soils areas at $2.13 \%$ of the total area of Al-Zawra park area. It was also ranging between $(0.4$ -0.3 ) in areas heavy with large trees planted intensively in that area of $1.25 \%$ of the park. Other values ranged between $(0.2-0.3)$ of areas planted with less intensive trees them previous of $12.4 \%$ of the total area of the park. NDVI ranged between $\quad(0.1-0.2)$ in areas planted separately with plants where this area formed $60.92 \%$ of the total park area. Last category ranged between $(0-0.1)$ where it include light vegetation cover of pale colors including weeds and grasses up to parking lots and empty spaces of (0) NDVI values at $23.30 \%$ of the total area of the park.

Keywords: geotechnical technologies, vegetation index NDVI, geographic information systems (GIS), remote sensing RS.

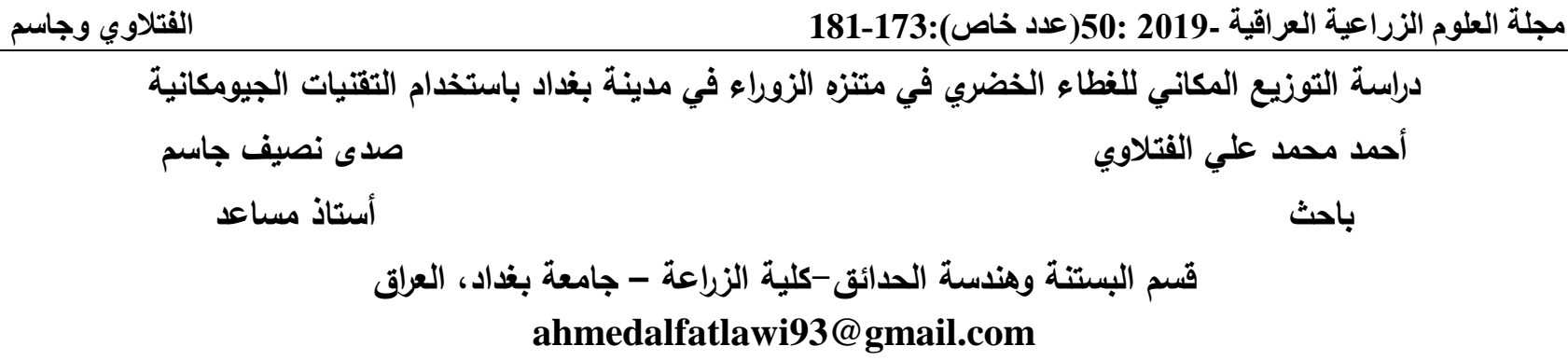




\section{INTRODUCTION}

Monitoring, estimating and categorizing vegetation from space is important for many activities related to land-use determination and natural resource management and reforestation efficiently as well as in combat desertification and the encroachment of urban cities on green areas (4). Recent attention has directed towards importance of urban parks as essential ingredients for development of the urban quality of life (3). Plant coverage is defined as the amount of vegetation covered soil surface, and is the result of interaction of dynamic natural factors and different human factors, the normalized difference vegetation index "NDVI" a simple equation that estimates reflection to two types of spectral beams (red and infrared), which is means of monitoring changes in vegetation, ranging from the value between $(-1$ and +1$)$, the Green Vegetation Index is associated with the quality of land cover (11). Whenever values of "NDVI" approaching $(+1)$ indicates thick vegetation, when approaching near (-1) refers soil (1). The relationship of the green vegetation account as in the following equation (18):

NDVI=(Band X-bandy)/ Band X +(Bandy).

Today the normalized difference vegetation index (NDVI)is mostly used to display this information. NDVI is an indicator of the density of chlorophyll in leaf tissue calculated from the red and near infrared bands: $\quad \mathrm{NDVI}=(\mathrm{NIR}-\mathrm{RED}) /(\mathrm{NIR}+\mathrm{RED})$. NDVI gives values between -1 and +1 where vegetated areas in general yield high positive values, while non-vegetated ground is found on the negative side (10). NDVI products, which have high temporal and spatial resolution, have been applied in scientific research19-21. Furthermore, measurement of AGB using MODIS-NDVI products would overcome the shortcomings of traditional measurement, offering increased effectiveness (13). The basis for the use of remote sensing data in detecting changes is that the change in the land cover should lead to changes in the radiation values received by the sensor, and changes in the radiation values resulting from the changes in the land cover should be significant when compared to the radiation changes resulting from other factors such as Different weather conditions or variations in the angle of the sun or a variation in soil moisture, as the effects of these factors can be reduced proportionally by choosing the appropriate data, for example, the satellite video captured by the lunar Land Sat8, which dates back to the same time of the year reduces the problems of different sun angle and soil moisture (6) Both Malini and Somashekar (14) conducted a comparative study of the distribution of vegetation for eight areas of the province using "NDVI" and satellite imagery for 2004, the results of the study indicated that there were statistically significant differences in the average values of the modified vegetation variation guide between regions Studied, a rise in the average values of "NDVI" in the "byatarayanur" and the lowest value in the "dsrahalli" area was noted and the study concluded that the assessment of vegetation could reflect the state of vegetation cover in the city and the consequent benefits to the state of the city. Vegetation density of the " GIR " National Park and the boundaries of the tropical forest area in the Gujarat" Indian province was assessed using geotechnical techniques; satellite imagery was adopted to obtain spatial data for the density of vegetation in this protected area, The results showed that approximately $63.5 \%$ of the studied area is covered with a density of $10-40 \%$, while $35.89 \%$ of the area is estimated to be $40 \%$ $70 \%$,the study concluded that the use of these techniques is very cost-effective, providing information at a high level of accuracy that is useful in biodiversity management and planning especially in the national parks and forestry sector (2). A study was conducted in the cities of Sosnowiec and Bedzin Zglebi Dabrowski Basin in southern Poland, with the aim of identifying major changes in the use of urban parklands, The study included two urban parks, Sielecki Park in Sosnowiec (10.4 hectares) and Gora Park in Bedzin area (6.7 ha), The results obtained with geographic information systems "GIS" indicated significant variations in terms of spatial changes and quality in the use Land in urban parks, as well as changes in urban planning strategies, GIS methods were useful in interpreting specific changes, The increase in forest areas was noted in 2009, and the study concluded that the use of GIS makes it easy to 
conduct studies based on old maps, contemporary cartographic materials and comparative analysis (5). Salah (17) implemented an integrated approach to remote sensing and GIS to assess the speed of Baghdad city urbanization for the period 1961 - 2002. Land-use patterns and ground cover have undergone a fundamental change due to the rapid expansion since 1958, as agricultural land uses have shifted Green to urban uses, in addition to the lack of proper land-use planning, has led to the urgent need to assess the size and pattern of Baghdad's urban growth and its environmental impact. Different types of vegetation derived from the imaging spectrophotometer can be classified as an advanced high-resolution device, as well as remote sensing (space visualization) and land images, and the vegetation index has been selected for this study to be less sensitive to topographic change in the regions Rugged Mountain (7) (16). The studied urbanized areas have the NDVI values by 15 to $45 \%$ lower than the corresponding areas at 20-40 $\mathrm{km}$ distance. The largest NDVI reduction is typical for the newly developed areas, whereas the older areas show recovery of the vegetation cover (8).

\section{Data sources}

1-Space visual for the study area captured by satellite Land8 and OLI with a spatial distinguishing capacity of $30 \times 30 \mathrm{~m}^{2}$ for the spectral package first, second, third, fourth, fifth, sixth and seventh in extent TIFF, of the study area from the division of Geographic Information System In the design section in Baghdad department and the date of capturing 4/7/ 2017, figure (1).

2-Geographic Information Systems Program GIS ARC V10.3.

\section{MATERIALS AND METHODS}

The normalized differences of Vegetation Index "NDVI" was studied by the ARC GIS v10.3 and using satellite imagery captured by the satellite Landsat 8 and the sensor OLI with a spatial discrimination capacity $30 \times 30 \mathrm{~m}^{2}$ (12), figure (1). the study area" Zawra Park "deduction for the purpose of studying the normalized differences of vegetation index
"NDVI" , as the satellite visible by satellite Land8. The central region of Iraq includes Baghdad province, which includes the study area, showed in (Figure 2). The former figure shows that the park site is ready for vegetation analysis, The packages that will be analyzed were determined accordingly and in the case Vegetarian index, we chose the fourth, fifth to calculate the index that represented the ratio between the infrared and the red bands of OLI to the sum of these two bands, the plant is characterized by other inversely a small amount of red wave length, reversing a large amount of near infrared, so it is possible to link the biomass to the vegetation and the values of the plant index that calculates the proportions of the red wave length and the range of wave length under The red near the next equation that was clarified by Tucker (18):

NDVI = (NIR-RED) / (NIR + RED)

NIR: Infrared wave length.

Red: Red wave length

Then press the analysis box where the program performs the analysis as the basis for the Green Vegetation Index is the light reflections coming from the fourth and fifth packages where the values of "NDVI" range from +1 to 0 and -1 , as the values are higher than 0 indicates a vegetation cover and the closer the value from +1 indicates a dense vegetation according to the recorded value, whereas the values are 0 and less indicate the absence of vegetation and the closer the value of "NDVI" than -1 , the lack of vegetation cover in conjunction with the rise of other layers, such as soil, water and other components, figures $(3,4)$ have shown Visual rating Analyzer reclassify. The visual analysis and visual categorization numbered as 1 and 2 respectively to calculate the percentage of each vegetation index value to convert the Raster to Polygon, choose the categorized visual and values to make the conversion process, figures $(5,6)$. After conversion process was finished, we imported a table of contents of the visual analysis that is converted to Microsoft Excel 2013 to make area calculations and percentages. 


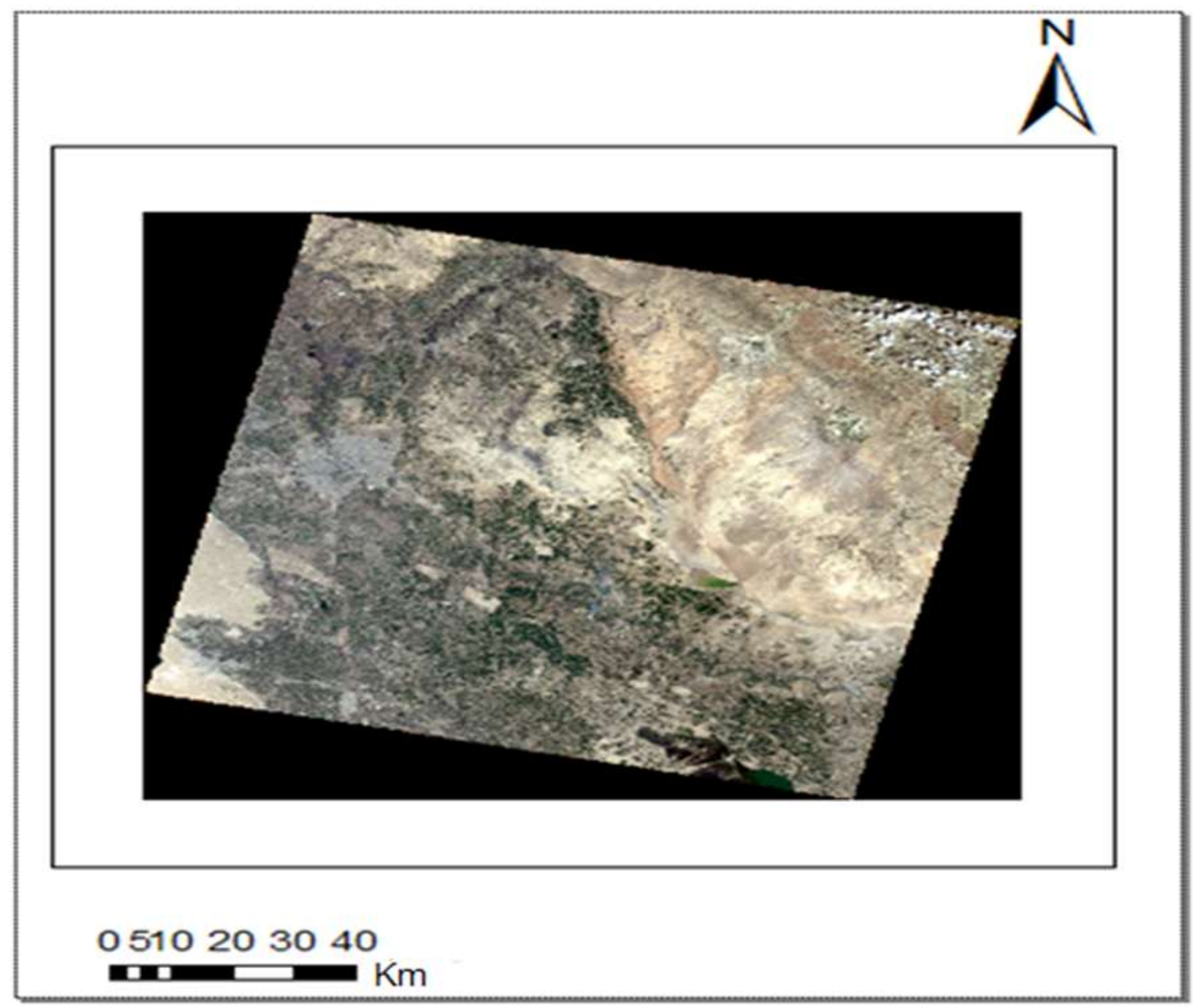

Figure 1. Satellite image of the study area

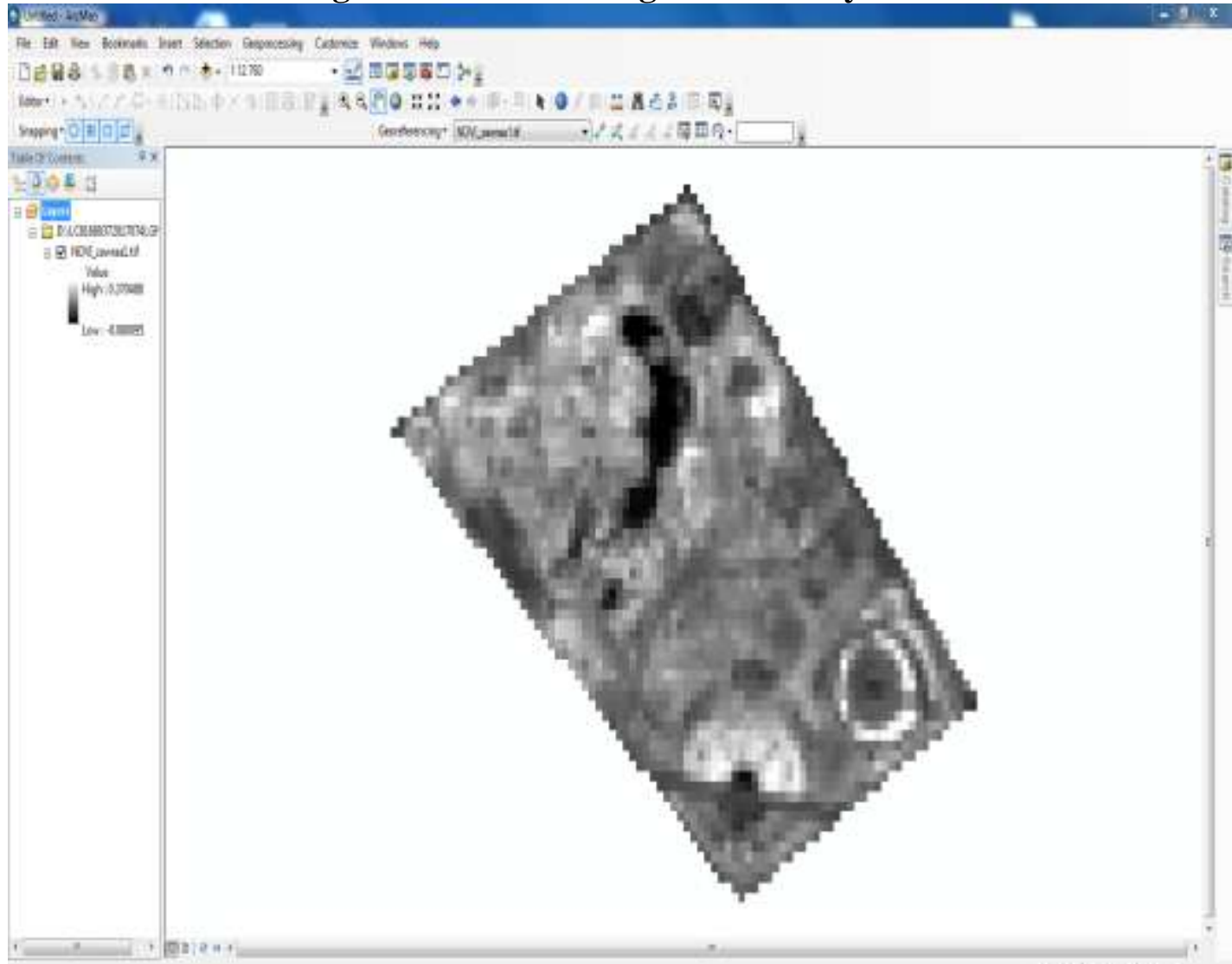

Figure 2. Study site subset 


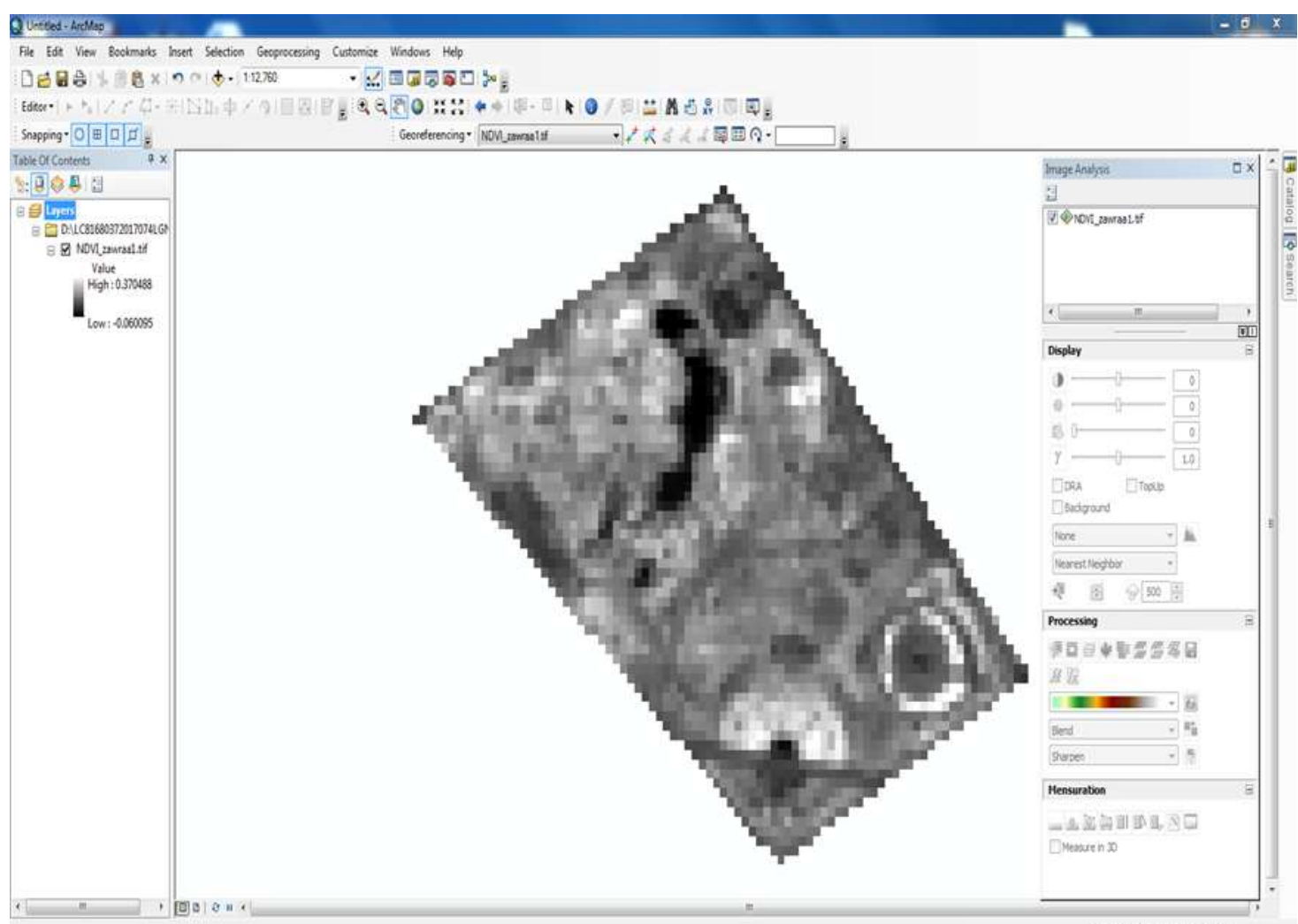

Figure 3. Visual interpretation of subset image

Reclassify

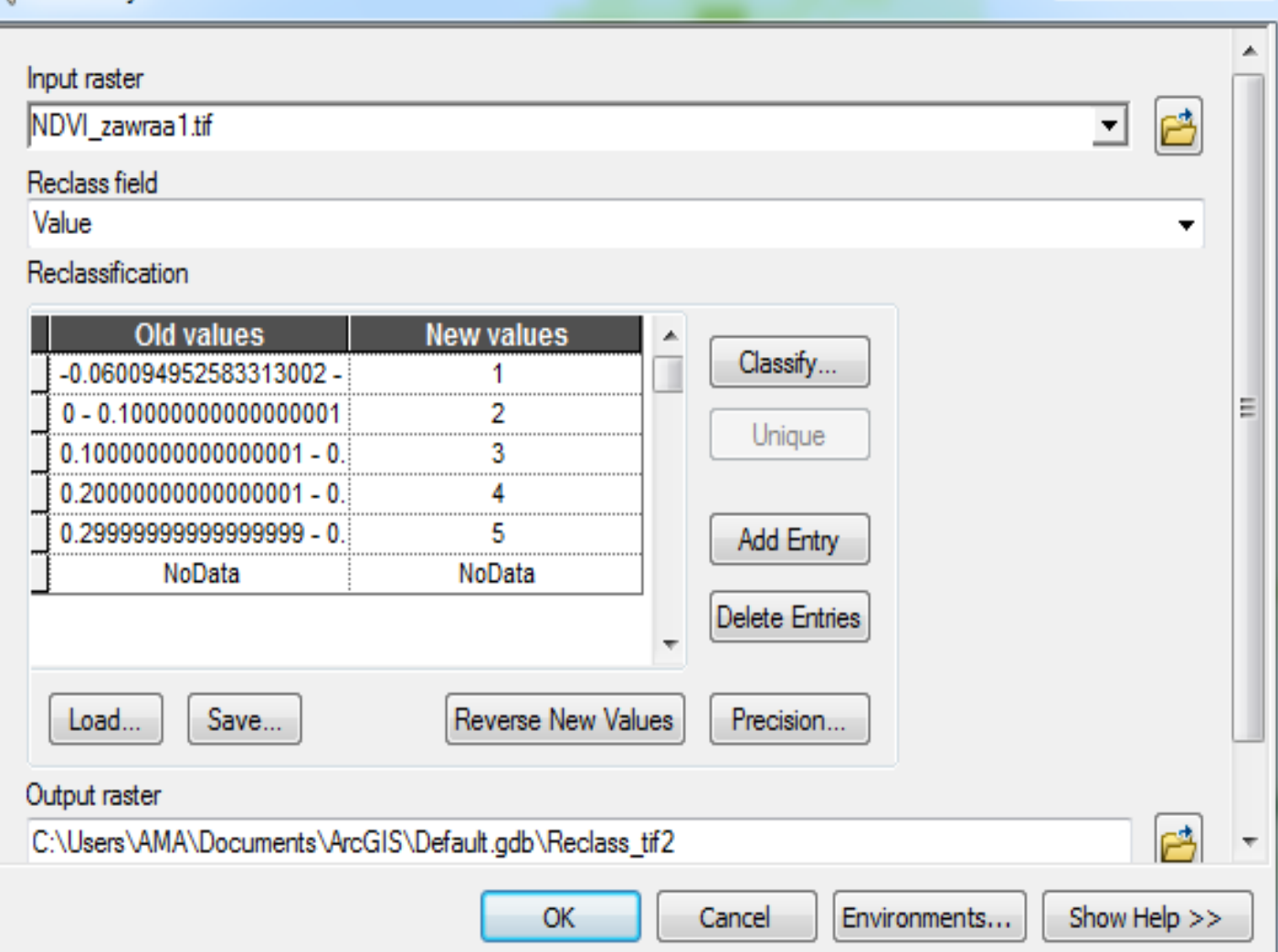

Figure 4.Re-classification window 


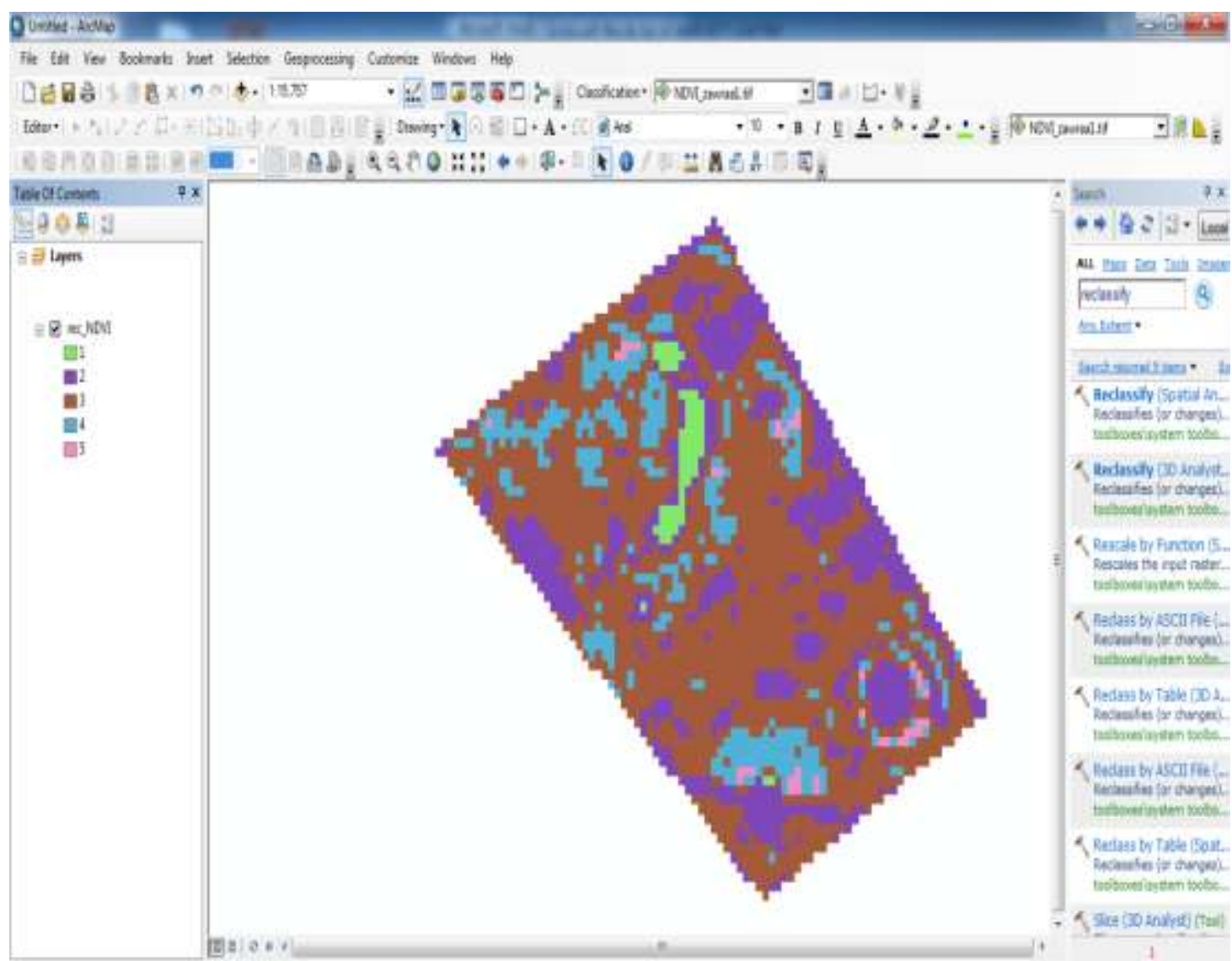

Figure5. Visual analysis Reclassification of the study area

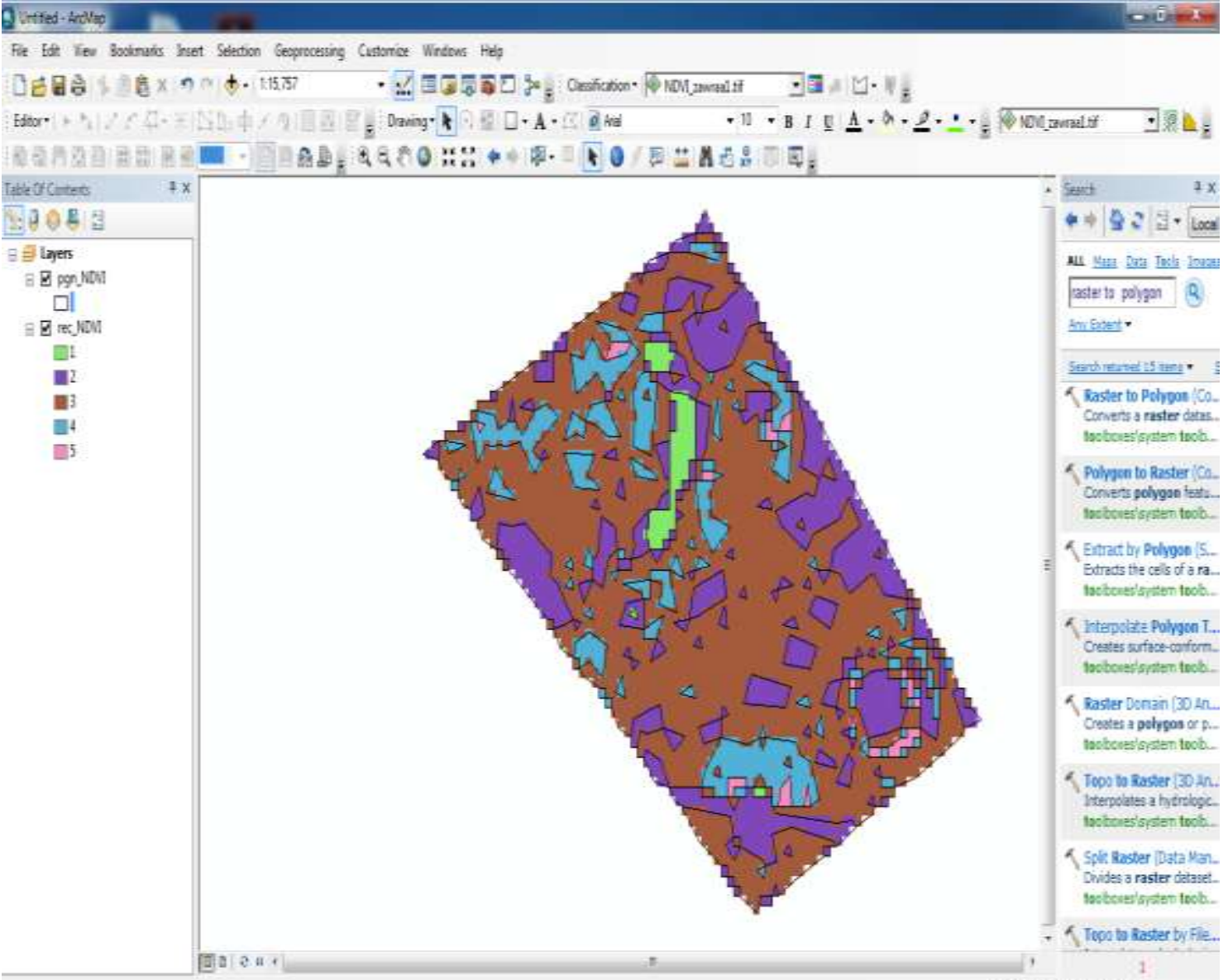

Figure 6. Raster Conversion to polygon 


\section{RESULTS AND DISCUSSION}

Figure (7) showed the spatial distribution of vegetation measured based on the normalized difference of vegetation index NDVI, it showed that it ranged from (-0.6 to 0.4$)$ where that the standard range for this index ranges from -1 to 1 (9). When comparing vegetation cover to the study area with vegetative cover varieties notes that the value is 0.4 of the high values, which refers to a heavy vegetation cover (15). That Vegetation index values in Al-Zawra Park ranged from (-0.06-0) in areas where vegetation is reduced where it include water bodies, empty land, and (0.3-0.4) in areas involving large, contiguous and dense trees. The rest of the values were $(0.2-0.3)$ in areas with vegetation that were planted in a contiguous, less than the previous and (0.1$0.2)$ in areas that include the pale green and plants cultivated separately, and finally (0.1-0) in the regions contain a lower green and pale colored plants such as bushes and grasses plants up to the parking lot areas. Empty areas with a value of (0) where vegetation cover is lacking as shown in figure (7) and table (1).

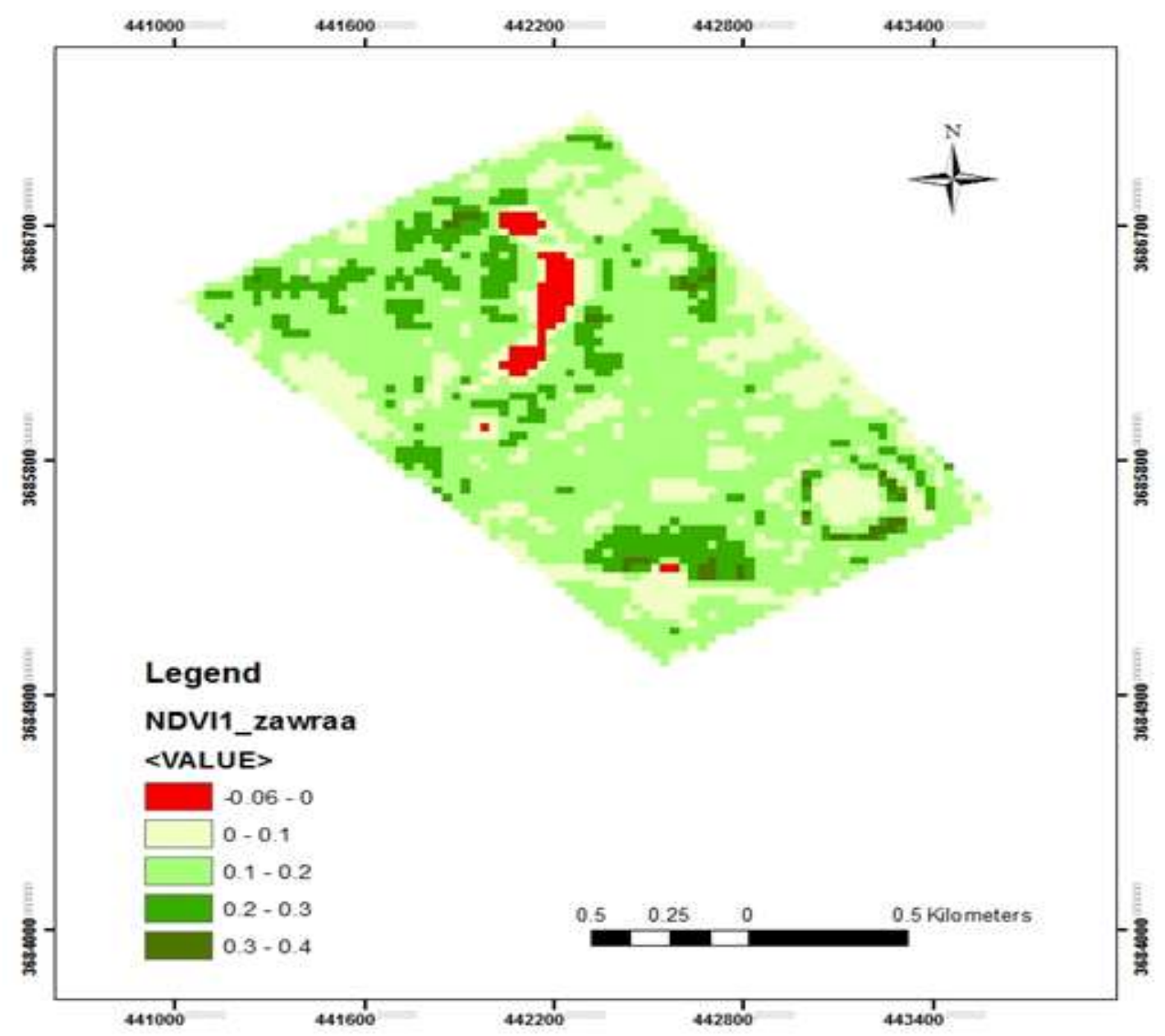

Figure 7. NDVI for Al-Zawra park - 2017

The proportion of regions without green vegetation is $2.13 \%$, including vegetation-free areas such as lakes, water bodies and places of living aquatic animals, roads, buildings, parking and barren land. With a low proportion of vegetation, area containing lowand pale-green surfaces and empty areas containing bushes vegetation at $23.30 \%$ of the park area, as compared to the average vegetation density $60.92 \%$ the areas containing the green vegetation and plants cultivated individually or separately. The proportion of dense vegetation covered by Albizzia, Eucalyptus and Ziziphus, olive trees, and hedges plants such as Ficus, Dodonia, Carissa and other plants at rate of $12.40 \%$, the proportion of very dense vegetation is $1.25 \%$ , The vegetation is very close and dense to a higher degree than the previous category as shown in Figure (8) and table (1). 


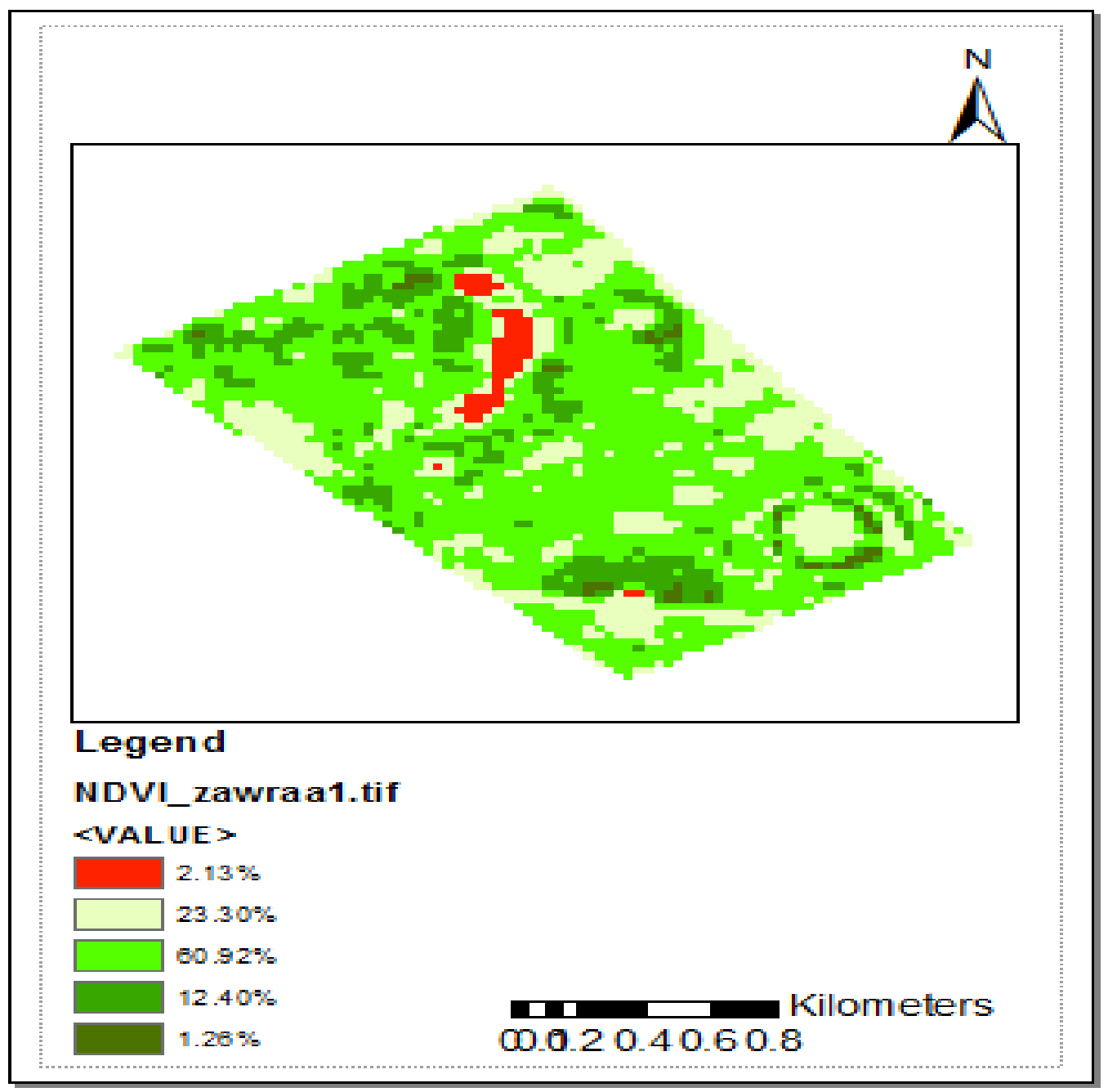

Figure 8.Percentages of the NDVI Al-Zawra park - 2017

Table1. Green Vegetation Guide Values "NDVI" and vegetation density Zawra park - 2017

\begin{tabular}{|cccc|}
\hline Color & Vegetation density & Plant coverage Ratio & Extent of NDVI values \\
\hline Red & Lack of vegetation cover & $2.13 \%$ & $-0.06-0$ \\
White & Low density & $23.30 \%$ & $0-0.1$ \\
Light Green & Medium density & $60.92 \%$ & $0.1-0.2$ \\
Green & Good density & $12.40 \%$ & $0.2-0.3$ \\
Dark Green & Very dense & $1.26 \%$ & $0.4-0.3$ \\
\hline
\end{tabular}

\section{REFERENCES}

1.Aghasi, B., A, Jalalian. and N, Honarjoo. 2011. Decline in soil quality as a result of land use change in Ghareh Aghaj watershed of Semirom, Isfahan, Iran. African Journal of Agricultural Research, 6(4): 992-997

2.Alam, M.S., J.A. Khan., B.J. Pathak., and S. Kumar., 2014. Assessment of forest density using geospatial techniques of a tropical protected area. International Journal of Scientific and Research Publications, 4(3): 1-6 3.Al-Bawi, S. K. A. and S. N. Jasim., 2016. Evaluation of design principles for Babylon Park. The Iraqi Journal of Agricultural Sciences, 47(4): 959-972, 2016.

4.Al-Hamami, A. T. S., and A. A. Al-Azzawi,. 2007. Use of remote sensing and GIS techniques in estimating the area and intensity of artificial forest fighting in the city of Mosul. The Journal of Education and Science. 14(3): $1-7$

5.Banaszek, J., M. Gajos., D. Karkosz., O. Rahmonov., and T. Parusel., 2014. Using GIS methods to investigate urban parks within Industrial Regions. Polish Journal of Environmental Studies, 23(2): 932-934

6.Bayan S., and H. Ahmad., 2013. Mangrove Forests mapping in the southern part of Japan using Landsat ETM+ with DEM, Journal of Geographic Information System, 5(1): 373

7.Couteron, P., P. Hunke., J. Bellot., J. Estrany., N. Martínez-Carreras., E.N. Mueller., V.P. Papanastasis., R.R. Parmenter., and J. Wainwright., 2014. Characterizing patterns. 
In Patterns of land degradation in drylands, Journal of Springer Netherlands, 6(3): 211-245 8.Esau, I., V.V. Miles., R. Davy., M.W. Miles., and A. Kurchatova., 2016. Trends in normalized difference vegetation index (NDVI) associated with urban development in northern West Siberia. Atmospheric Chemistry and Physics, 16(15): 9563-9577

9.Hayes, D.J. and S. A. Sader., 2001. Comparison of change-detection techniques for monitoring tropical forest clearing and vegetation regrowth in a time series. Photogrammetric Engineering and Remote sensing, 67(9): 1067-1075

10.Johansen, B. and H. Tommervik., 2014. The relationship between phytomass, NDVI and vegetation communities on Svalbard. International Journal of Applied Earth Observation and Geoinformation, 27(2): 20-30

11.Karaburun, A., 2010. Estimation of C factor for soil erosion modeling using NDVI in Buyukcekmece watershed. Ozean Journal of applied sciences, 3(1): 77-85

12.Krygier, J. and D. Wood., 2016. Making maps: a visual guide to map design for GIS. Guilford Publications
13.Liu, S., F. Cheng., S. Dong., H. Zhao., X. Hou., and X. Wu., 2017. Spatiotemporal dynamics of grassland aboveground biomass on the Qinghai-Tibet Plateau based on validated MODIS NDVI. Scientific Reports, 7(1): 4182

14.Malini, A.S. and R.K. Somashekar., 2014. Assessment of vegetation cover through NDVI, Bangalore India. Indian Journal of Applied Research, 4(3): 176-179

15.Muttitanon, W. and N. K. Tripathi., 2005. Land use/land cover changes in the coastal zone of Ban Don Bay, Thailand using Landsat 5 TM data. International Journal of Remote Sensing, 26(11): 2311-2323

16.Ndayisaba, F., H. Guo., A. Bao., H. Guo., F. Karamage., and A. Kayiranga., 2016. Understanding the spatial temporal vegetation dynamics in Rwanda. Remote Sensing, 8(2): 129

17.Salah, S.A., 2011. Impact of urban expansion on surface temperature in Baghdad, Iraq using remote sensing and GIS techniques. Canadian Journal on Environmental, Construction and Civil Engineering, 2(8): 193-202.

18.Tucker, C.J., 1980. A spectral method for determining the percentage of green herbage material in clipped samples. Remote Sensing of Environment, 9(2): 175-181. 